\title{
Polishing of CVD Diamond Films in Vacuum
}

Yongtao Ma, Yanmin Li, Zhanshu He

School of mechanical engineering, Zhengzhou University, Science Road 100, Zhengzhou, China, 450001 E-mail: myt@zzu.edu.cn, ymli64@zzu.edu.cn, hezhanshu@zzu.edu.cn

An efficient polishing process has been carried out at the polishing speed about $200 \mathrm{~mm} / \mathrm{s}$ in vacuum with temperature of $850^{\circ} \mathrm{C}$. With the polishing time reaches $120 \mathrm{~min}$, the surface roughness of polished could get to Ra0.016 compared to original Ra9.67. Mass loss rate per hour was used to quantify the polishing efficiency. Increasing the polishing pressure could get high mass loss rate, which could be used in the rough machining process. In fine machining process, the polishing pressure should be lower and the high polishing speed should be remained. The 3D morphology from atomic force microscope(AFM) shows there are some summits about 30-40nm in height, and the summits take into the shape of directional narrow cone.

Keywords: CVD diamond, Polishing, Vacuum

\section{Acknowledgments}

This work was supported by the National Natural Science Foundation of China [Grant number 51305136].

\section{References}

[1] MALSHE, A. P., PARK, B. S., BROWN, W. D. (1999). A review of techniques for polishing and planarizing chemically vapor-deposited (CVD) diamond films and substrates. In: Diamond and Related Materials, Vol. 8, No. 7, pp. 11981213. Elsevier, Amsterdam.

[2] PACE, E., PINI, A., CORTI, G. (2001). CVD diamond optics for ultraviolet. In: Diamond and Related Materials, Vol. 10, No. 3, pp. 736-743. Elsevier, Amsterdam.

[3] COE, S. E., SUSSMANN, R. S. (2000). Optical, thermal and mechanical properties of CVD diamond. In: Diamond and Related Materials, Vol. 9, No. 9, pp. 1726-1729. Elsevier, Amsterdam.

[4] SNAIL, K. A. (1991). CVD diamond as an optical material for adverse environments. In: Optical Surfaces Resistant to Severe Environments, Vol. 1330, pp. 46-64. SPIE, San Diego

[5] ZAITSEV, A. M., KOSACA, G., RICHARZ, B. (1998). Thermochemical polishing of CVD diamond films. In: Diamond and Related Materials, Vol. 7, No. 8, pp. 1108-1117. Elsevier, Amsterdam.

[6] YOSHIKAWA, M. (1990). Development and performance of a diamond-film polishing apparatus with hot metals. In: Diamond Optics III, Vol. 1325, pp. 210-221. SPIE.

[7] YOSHIKAWA, M., OKUZUMI, F. (1997). Hot-iron-metal polishing machine for CVD diamond films and characteristics of the polished surfaces. In: Surface and Coatings Technology, Vol. 88, No. 1, pp. 197-203. Elsevier, Amsterdam.

[8] SUZUKI, K., IWAI, M., UEMATSU, T. (2003). Material removal mechanism in dynamic friction polishing of diamond. In: Key Engineering Materials, Vol. 238, pp. 235-240. Trans Tech Publications, Switzerland.

[9] CHEN, Y., ZHANG, L. C., ARSECULARATNE, J. A. (2006). Polishing of polycrystalline diamond by the technique of dynamic friction, part 1: Prediction of the interface temperature rise. In: International Journal of Machine Tools and Manufacture, Vol. 46, No. 6, pp. 580-587. Elsevier, Kidlington.

[10] SCHUELKE, T., GROTJOHN, T. A. (2013). Diamond polishing. In: Diamond and Related Materials, Vol. 32, pp. 1726. Elsevier, Amsterdam.

[11] YUAN, Z., JIN, Z., KANG, R. (2012). Tribochemical polishing CVD diamond film with FeNiCr alloy polishing plate prepared by MA-HPS technique. In: Diamond and Related Materials, Vol. 21, pp. 50-57. Elsevier, Amsterdam.

[12] HUANG, S. T., ZHOU, L., XU, L. F. (2010). A super-high speed polishing technique for CVD diamond films. In: Diamond and Related Materials, Vol. 19, No.10, pp. 1316-1323. Elsevier, Amsterdam.

[13] TOTKA, B., PETR, L., LUKÁŠ, V. (2014). The use of optical microscopy to evaluate the tribological properties. In: Manufacturing Technology, Vol.14, No. 3, pp. 256-261. J. E. Purkyne University, Czech Republic.

[14] TOMÁŠ, H., PAVOL, H., MIROSLAVA, Ť. (2014). Coating surface roughness measurement made on coining dies. In: Manufacturing Technology, Vol.14, No. 3, pp. 309-317. J. E. Purkyne University, Czech Republic.

[15] JAN, P., ALEXEY, M. (2014). 3D measurement of surface texture parameters. In: Manufacturing Technology, Vol.14, No. 4, pp. 596-600. J. E. Purkyne University, Czech Republic. 